\title{
NEW DATA ON DIRECT ION STORAGE DOSEMETERS
}

\author{
Hermann Fuchs ${ }^{1, *}$, Simon Stähler ${ }^{2}$ and Michael Dittmar ${ }^{3}$ \\ ${ }^{1}$ TU Wien, Haberlgasse 77/10, A-1160 Vienna, Austria \\ ${ }^{2}$ Brockhausstrae 20, D-04229 Leipzig, Germany \\ ${ }^{3}$ ETH Zurich, Department of Physics, Institute for Particle Physics, Schafmattstrasse 20, CH-8093 Zurich, \\ Switzerland
}

Received February 27 2007, amended April 3 2007, accepted April 62007

\begin{abstract}
The DIS-1 dosemeter from the Finnish company RADOS is an innovative kind of passive electronic dosemeter for photon and beta radiation. This study examines the 'long-term' linear response behaviour, the calibration and readout accuracy with large samples of 'used' DIS-1 dosemeters especially in the low-dose region, which is of special interest for radiation protection issues. Our measurements prove the adequacy of the DIS-1 dosemeter for long-term-personal dosimetry. The fast and precise readout seems to make the DIS-1 dosemeter an ideal choice for personal dosimetry in low-dose environments.
\end{abstract}

\section{INTRODUCTION}

For the past few years, an innovative kind of passive electronic dosemeter, the so-called DIS-1 dosemeter from the Finnish company RADOS, for photon and beta radiation has become available. After having been tested at the STUK Radiation Metrology Laboratory in Finland ${ }^{(1)}$ and the PSI (Paul Scherrer Institute) in Switzerland, (2), it has been approved by the swiss government for legal use in 1999. In 2002, another study on the DIS-1 dosemeter was done at the PSI ${ }^{(3)}$, during which a field test and tests concerning the long-term stability of the dose signal have been carried out.

Previous tests, based on 'new' dosemeters, have shown very good behaviour. In this study, the authors examine the 'long-term' linear response behaviour and the calibration and readout accuracy with much larger samples of 'used' dosemeters. The focus of this study lies in the low-dose region, which is of special interest for radiation protection issues. Special attention has been given to assure all dosemeters have been in use for some time (typically one year) and to guarantee different production series have been used.

\section{DESIGN OF THE DIS-1 DOSEMETER}

The DIS-1 dosemeter is based on Direct Ion Storage technology. The base component is a MOSFET transistor. The surface of the floating gate is surrounded by an air space, the so-called ionization chamber. The charge of the floating gate is initially set to a predetermined value. Due to ionization occurring in the ionization chamber, the charge on

*Corresponding author: hermann.fuchs@student.tuwien. ac.at the floating gate is subject to change. By measuring the resistance of the MOSFET transistor, which is determined by the adjacent charge of the floating gate, the absorbed dose can be measured. After conversion the absorbed dose is displayed on the DBR-1 reader. The dosemeter is designed to measure the dose equivalent $H_{p}(10), H_{p}(0.07)$ of photon and at the same time the $H_{p}(0.07)$ dose equivalent of beta irradiation covering a dose range from a few $\mu \mathrm{Sv}$ up to $30 \mathrm{~Sv}$. To achieve this five different ionization chambers are used. The change from one ion chamber to the other takes place automatically.

\section{IRRADIATION CONDITIONS}

The irradiations were performed at room temperature. During irradiations, the dosemeters were mounted on an ISO water-slab-phantom ${ }^{(4)}$ of the size $30 \times 30 \times 10 \mathrm{~cm}$. In this study, 50 randomly selected dosemeters from the CERN dosemeter pool have been used. Each dosemeter has been in use for typically one year. Depending on the measurements, doses have been applied both segmented in small dose steps (i.e. to rule out systematics like the buildup of small incremental errors) and en bloc (Table 1).

In order to minimize the influences of the irradiation mechanism, all irradiations have been kept above $100 \mathrm{~s}$. To achieve this, the distance of the source to the phantom has been varied from $20 \mathrm{~cm}$ to $4 \mathrm{~m}$. Furthermore, three different ${ }^{137} \mathrm{Cs}$ sources (Table 2) with different intensities have been used. This setup ensures a precise dose application. Irradiations have been performed under secondary electron equilibrium using a 5-mm thick Perspex plate. For the calculation of the $H_{p}(10)$ and $H_{p}(0.07)$ 
Table 1. Applied irradiations for first analysis.

\begin{tabular}{lcc}
\hline Irradiated dose & $\begin{array}{c}\text { Number of } \\
\text { dosemeters }\end{array}$ & $\begin{array}{c}\text { Source } \\
\text { ID }\end{array}$ \\
\hline $10 \times 5 \mu \mathrm{Sv}$ & 16 & 3740 \\
$10 \times 10 \mu \mathrm{Sv}$ & 32 & 3609 \\
$10 \times 100 \mu \mathrm{Sv}$ & 32 & 2045 \\
$10 \times 1 \mathrm{mSv}$ & 32 & 2045 \\
$10 \mathrm{mSv}+10 \times 1 \mathrm{mSv}+10 \mathrm{mSv}$ & 16 & 2045 \\
\hline
\end{tabular}

doses, a special program ${ }^{(5)}$ using the conversion coefficients of the ISO Standard 4037-3 has been used.

\section{DATA AND ANALYSIS}

\section{Correction factor}

Due to the randomly selected dosemeters from different production batches, slight differences in calibration could not be avoided (Figures 1 and 2). In order to minimize the influences of improperly calibrated dosemeters, a correction factor had to be calculated. Using an irradiated dose of $1 \mathrm{mSv}$ as a reference, an individual correction factor for each dosemeter has been established. This correction factor was applied to all measurements.

\section{Calibration}

The quality of the calibration was measured by irradiating all dosemeters with a reference dose of $1 \mathrm{mSv}$. The mean measured dose value was found to be $4.5 \%$ lower than the irradiated dose (Figures 1 and 2). This might be due to a calibration mismatch between the calibration system at RADOS and CERN. An interlaboratory comparison is planned to rule out such differences.

\section{Summation of applied doses, response and linearity}

The authors wanted to find out, if small doses could be added arbitrarily. To do this, the response and linearity of the dosemeters have been examined. Groups of 16 and more dosemeters have been formed and examined them in the range of $5 \mu \mathrm{Sv}$ up to $30 \mathrm{mSv}$ (Table 1). In this range, the two chambers (DS and DL chamber) with the highest sensitivity

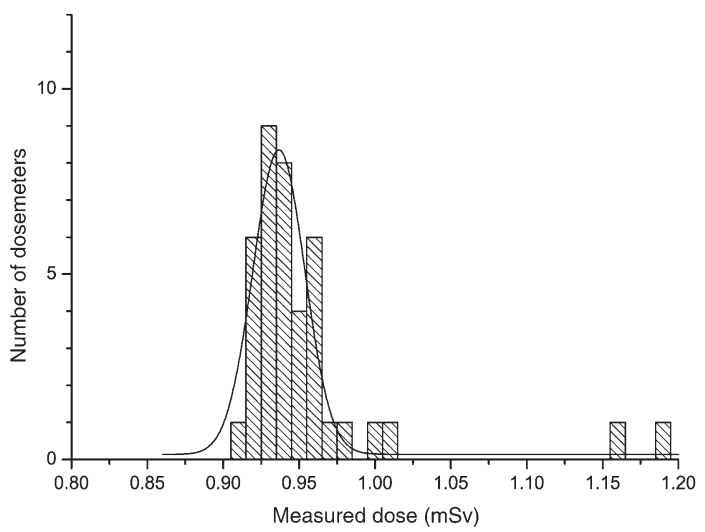

Figure 1. Measured $H_{p}(10)$ dose of the most sensitive chamber (DS), irradiated with $1 \mathrm{mSv}$, without correction factor.

have been examined. Special attention has been given to the low-dose range, where irradiations have been performed using $5 \mu \mathrm{Sv}$ steps. All dosemeters have been read out after each irradiation. This enabled us to compare the dose values of different dosemeters with different irradiation steps.

The response proved to be highly linear (Figure 3). The deviation of the average response was found to be $< \pm 2 \%$. The standard deviation of the mean value for the two chambers can be found in Table 3. The mean value of the response of all dosemeters has been determined. After normalizing and plotting vs. the dose value, the so-called normalized response was found (Figure 4).

\section{Readout accuracy}

The authors wanted to measure the readout accuracy of the DBR-1 reader. In order to measure this readout accuracy, multiple readouts of the dosemeters have been performed after each of subsequent irradiations steps. All readouts have been done using the DBR-1 reader. A small correlation between readout error and irradiated dose has been found at the most sensitive chamber (DS). However, the resulting readout error $\left[(8 \pm 4) \times 10^{-3} \%\right.$ of the irradiated dose] is extremely small and this correlation can therefore be neglected (Figure 5). At the other

Table 2. Sources used for irradiation.

\begin{tabular}{lcccc}
\hline Number & Source & Activity & Dose rate & $\gamma$-energy \\
\hline 2045 & ${ }^{137} \mathrm{Cs}$ & $1.02 \mathrm{TBq}$ & $10-92 \mathrm{mSv} \mathrm{h}^{-1}$ & $662 \mathrm{keV}$ \\
3609 & ${ }^{137} \mathrm{Cs}$ & $86.8 \mathrm{GBq}$ & $0.38-7.91 \mathrm{mSv} \mathrm{h}^{-1}$ & $662 \mathrm{keV}$ \\
3740 & ${ }^{137} \mathrm{Cs}$ & $12.1 \mathrm{GBq}$ & $0.05-1.12 \mathrm{mSv} \mathrm{h}^{-1}$ & $662 \mathrm{keV}$ \\
\hline
\end{tabular}




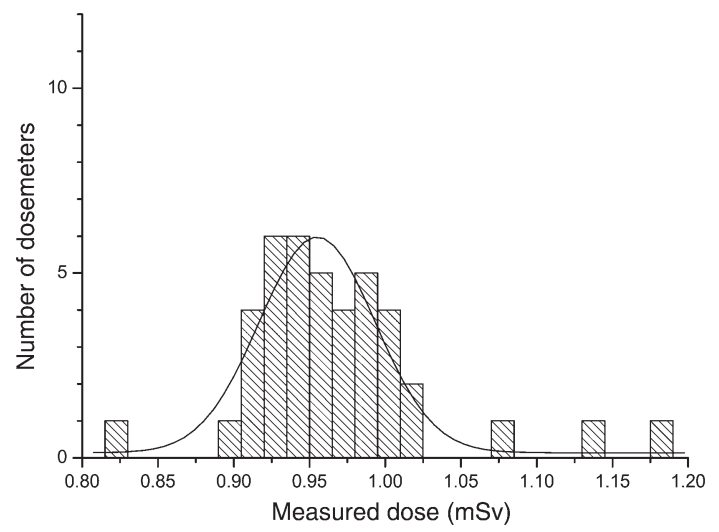

Figure 2. Measured $H_{p}(0.07)$ dose of the most sensitive chamber (DS), irradiated with $1 \mathrm{mSv}$, without correction factor.

chamber (Figure 6) (DL) no such correlation has been found. Furthermore, the authors could not find any evidence, that multiple readouts would influence the registered dose value.

\section{Long-term stability of the dose value (fading)}

Previous tests have shown an initial dose decrease of $2 \%$ after irradiation, until the dose value stabilizes. In order to study the long-term stability of the dose value with used dosemeters, 24 dosemeters have been given an initial dose of $3 \mathrm{mSv}$. Repeated readouts have been carried out over a period of $124 \mathrm{~h}$. The measurements have been background corrected using data of a non-irradiated control group consisting of eight dosemeters, which have been stored

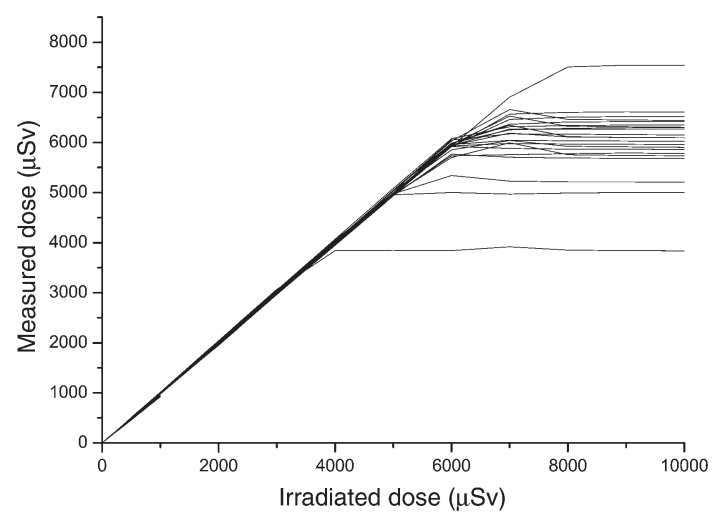

Figure 3. Measured dose vs. irradiated dose, DS chamber, using 32 dosemeters. The saturation of the DS chamber can be seen. The DS chamber is normally used to measure doses up to $3 \mathrm{mSv}$.
Table 3. Standard deviation of the mean response value for the DS and DL chamber, measured during irradations from $5 \mu \mathrm{Sv}$ up to $30 \mathrm{mSv}$.

\begin{tabular}{lcc}
\hline $\begin{array}{l}\text { Measurement } \\
\text { range }\end{array}$ & $\begin{array}{c}\text { Standard } \\
\text { deviation } \\
{\left[10^{-3_{0}}\right]}\end{array}$ & $\begin{array}{l}\text { Number of } \\
\text { dosemeters }\end{array}$ \\
\hline DS-chamber & & \\
$20-100 \mu \mathrm{Sv}$ & 2.9 & 24 \\
$100-1000 \mu \mathrm{Sv}$ & 2.8 & 32 \\
$1-4 \mathrm{mSv}$ & 2.7 & 32 \\
DL-chamber & & 24 \\
$100-1000 \mu \mathrm{Sv}$ & 7.1 & 16 \\
$1-30 \mathrm{mSv}$ & 2.7 & \\
\hline
\end{tabular}

under the same conditions. Within the first $24 \mathrm{~h}$, the average dose value diminished $0.4 \% \pm 0.1 \%$. After $24 \mathrm{~h}$, the dose value stabilized (Figure 7) and remained constant. The difference between our measurements and previous tests indicates that a previous version of the DIS-1 dosemeter might have been used during previous tests ${ }^{(3)}$.

\section{Results and conclusion}

Given the known non-linearities of other dosemeter designs, non-linearities in the response have been expected. This could not be confirmed. The response proved to be highly linear with a deviation of the average response of only $< \pm 2 \%$, which is an excellent value for a personal dosemeter. The observed calibration mismatch of $4.5 \%$ is probably due to a mismatch between the calibration systems at RADOS and CERN. An interlaboratory comparison is planned to avoid further differences. A suspected readout inaccuracy could not be found. Our measurements of long-term fading of the dose value have proven to be much lower than previous

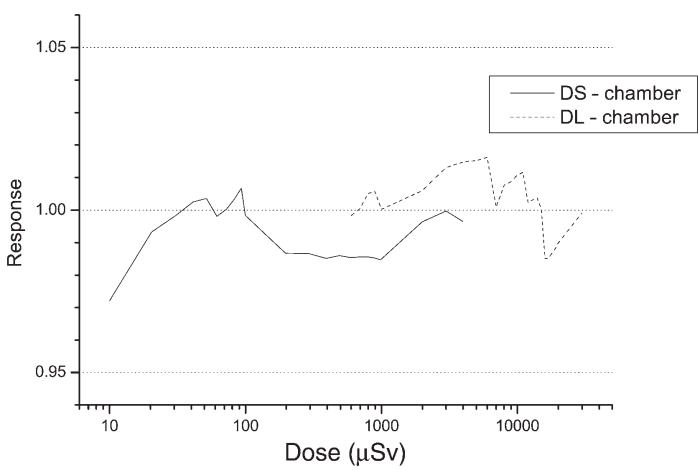

Figure 4. Normalized response of the two most sensitive (DS and DL) chambers, measured from $5 \mu \mathrm{Sv}$ to $30 \mathrm{mSv}$. 


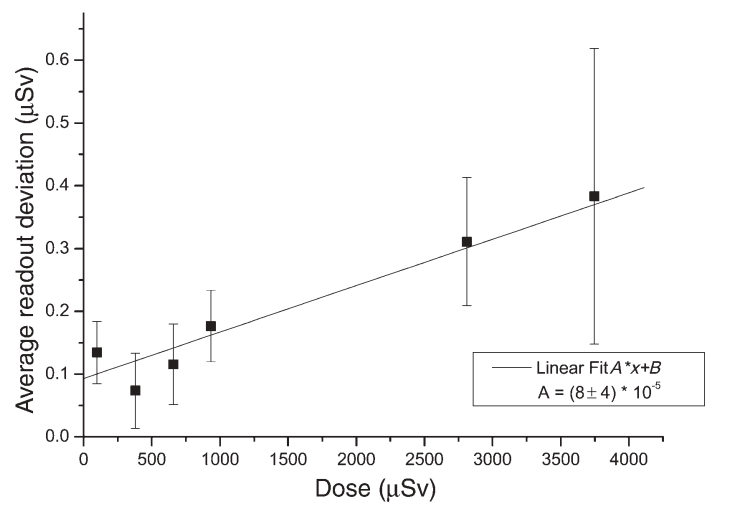

Figure 5. Average readout deviation during multiple readouts using the DBR-1 reader, with error bars, low-dose range, DS-chamber.

measurements. This can probably be explained by a revised dosemeter design.

Our measurements prove the adequacy of the DIS-1 dosemeter for long-term personal dosimetry. The fast and precise readout seems to make the DIS-1 dosemeter an ideal choice for personal dosimetry in low-dose environments.

\section{ACKNOWLEDGEMENTS}

We would like to thank the CERN radioprotection group for the hospitality and the possibility to use

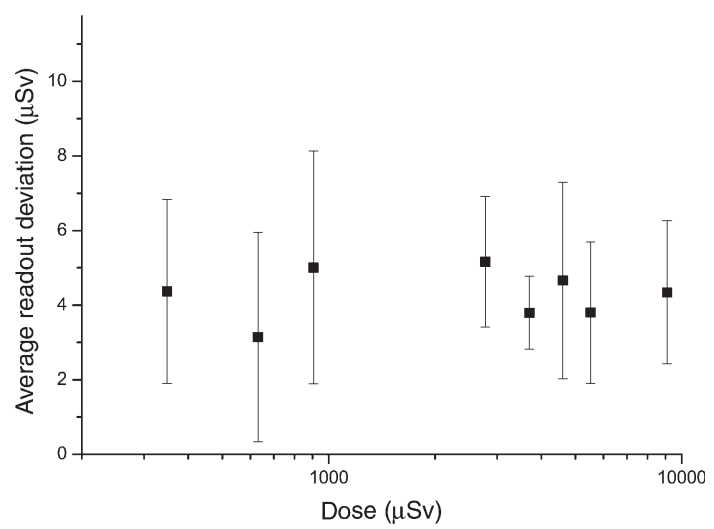

Figure 6. Average readout deviation during multiple readouts using the DBR-1 reader, with error bars, medium dose range, DL-chamber.

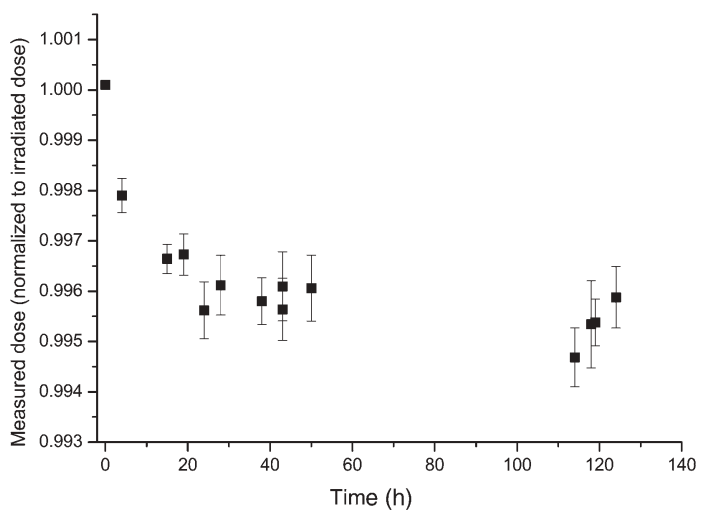

Figure 7. Time dependence of the dose value after an initial irradiation of $3 \mathrm{mSv}$. To increase readability, the data were normalized to the initial irradiation, the background was corrected using eight reference dosemeters.

their equipment to perform the measurements reported here. We are especially grateful to Dr. T. Otto for the idea to investigate the linearity of the dosimeters in detail and his efforts and help to complete this work and also for the many detailed discussions related to radiation and radiation protection. We would also like to thank P. Carbonez for the help and explanations about using the radiation equipment from the CERN radioprotection group. We are also grateful to Prof. F. Pauss, who supported that this work could be done as part of the stimulating research activities of her group.

\section{REFERENCES}

1. Jokelainen. Test Report No T/3/99-DIS-1 Detector Type Test Report (STUK Radiation Metrology Laboratory) (1999).

2. Wernli, C., Fiechtner, A. and Kahilainen, J. The Direct Ion Storage Dosemeter for the measurement of photon, beta and neutron dose equivalents. Radiat. Prot. Dosim. 84, 331-334 (1999).

3. Boschung, M., Fiechtner, A. and Wernli, C. A legally approved personal dosemeter for photon and beta radiation based on direct ion storage. Radiat. Prot. Dosim. 101, 271-274 (2002).

4. Alberts, W. G., Böhm, J., Kramer, H. M., Ites, W. J., Schwartz, R. B. and ThompsonI, M. G. International Standartisation of Reference Radiations and Calibration Procedures of Radiation Protection Instruments. In: Strahlenschutz: Physik und Messtechnik, Band 1, Kölzner, W. and Maushart, R. Eds. (Köln: TÜV Rheinland GmbH) (1994). pp. 181-188

5. Otto, T. and Carbonez, P. Irradiation Time Calculation Program (Radiation Protection Group, CERN) (2000). 